\section{Commentary: Concomitant surgical ablation of atrial fibrillation is safe in elderly patients}

\author{
Leonid Sternik, MD
}

I congratulate Petersen and colleagues ${ }^{1}$ on their very important article in this issue of the Journal. This study describes 556 patients who underwent concomitant surgical ablation of atrial fibrillation (AF). I have to confess that I was a bit disappointed by the only $62 \%$ to $72 \%$ freedom from recurrent AF 1 year after surgery. In this group, $43.6 \%$ of patients were in paroxysmal AF before surgery. So for these patients, I would expect much better results.

Petersen and colleagues ${ }^{1}$ used monopolar radiofrequency ablation in almost $60 \%$ of cases. As we know, it is difficult to achieve a reliable transmural lesion with monopolar radiofrequency devices. ${ }^{2}$ Of these patients, $13.9 \%$ underwent pulmonary vein isolation only. This lesion type proved to be insufficiently effective. ${ }^{3} \mathrm{I}$ am therefore sure that with the use of proper devices and lesion set, Petersen and colleagues ${ }^{1}$ could have achieve significantly better freedom from AF after ablation. Despite these drawbacks, I think that this article is very important. Petersen and colleagues ${ }^{1}$ showed that AF ablation is as effective in elderly patients as in younger patients, excluding coronary artery bypass cases. They also found no ablation-related complications.

In the modern era, we operate on elderly patients more frequently than in the past. People live longer and are also interested in a good quality of life in advanced age. That is why the understanding of the results of cardiac surgery in elderly patients is so important now. Interesting information is coming from comparisons of transcatheter to surgical aortic valve replacement. The most recent, a propensity score-matched analysis of low-risk elderly patients undergoing surgical and transcatheter aortic valve replacement, demonstrated an operative mortality of $1.1 \%$ and excellent

From the Department of Cardiac Surgery, Sheba Medical Center, Ramat Gan, Israel. Disclosures: Author has nothing to disclose with regard to commercial support.

Received for publication Oct 18, 2019; revisions received Oct 18, 2019; accepted for publication Oct 18, 2019; available ahead of print Oct 31, 2019.

Address for reprints: Leonid Sternik, MD, Department of Cardiac Surgery, Sheba Medical Center, Ramat Gan, Israel 5265601 (E-mail: Leonid.sternik@sheba. health.gov.il).

J Thorac Cardiovasc Surg 2021;161:1824-5

$0022-5223 / \$ 36.00$

Copyright (c) 2019 by The American Association for Thoracic Surgery

https://doi.org/10.1016/j.jtcvs.2019.10.093

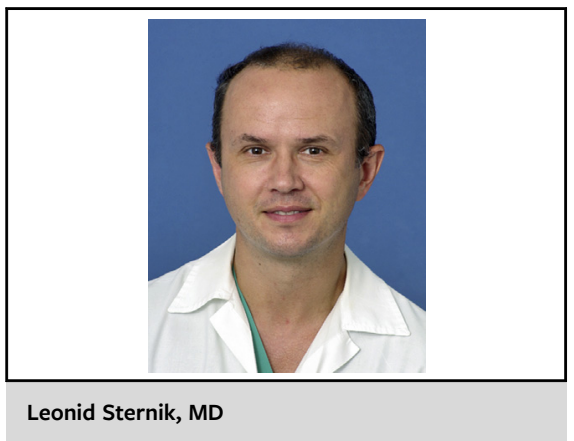

CENTRAL MESSAGE

Concomitant atrial fibrillation

ablation is as effective in elderly

patients as it is in younger pa-

tients. Ablation does not add

morbidity and mortality and may

improve early and late results.

long-term results in the surgical group. The survivals at 3 and 5 years after surgery were significantly better than with transcatheter aortic valve implantation. ${ }^{4}$ Iturra and colleagues ${ }^{5}$ published results of surgical aortic valve replacement in moderate risk patients. The median age was 80 years. Early mortality was $2.8 \%$, and the stroke rate was $1.8 \%$. We can understand from these studies that elderly patients can undergo heart surgery very safely in the modern era.

Petersen and colleagues ${ }^{1}$ mentioned several important studies in the Discussion section of their article. Badhwar and coworkers, ${ }^{6}$ in analysis that comparted 28,739 patients with $\mathrm{AF}$ who received surgical ablation with patients with $\mathrm{AF}$ without ablation showed that the patients undergoing surgical ablation had lower early mortality and incidence of neurologic event. ${ }^{6}$ Patients with AF undergoing coronary artery bypass grafting ${ }^{7}$ as well as aortic valve surgery ${ }^{8}$ but not undergoing concomitant $\mathrm{AF}$ ablation demonstrated increased morbidity and mortality relative to patients with concomitant AF ablation.

I conclude that concomitant surgical AF ablation should be performed in elderly patients. Generally, results of cardiac surgery in patients of this age are excellent in the modern era. Concomitant AF ablation does not add morbidity and mortality, and according to many studies it may improve early and late surgical results. No doubt concomitant ablation should be avoided in some difficult clinical cases; in most cases, however, the concomitant ablation must be performed in elderly patients. 


\section{References}

1. Petersen J, Vettorazzi E, Hakmi S, Alassar Y, Meyer C, Willems S, et al. Should concomitant surgical ablation for atrial fibrillation be performed in elderly patients? J Thorac Cardiovasc Surg. 2021;161:1816-23.e1.

2. Thomas SP, Guy DJ, Boyd AC, Eipper VE, Ross DL, Chard RB. Comparison of epicardial and endocardial linear ablation using handheld probes. Ann Thorac Surg. 2003;75:543-8.

3. Melby SJ, Zierer A, Bailey MS, Cox JL, Lawton JS, Munfakh N, et al. A new era in the surgical treatment of atrial fibrillation: the impact of ablation technology and lesion set on procedural efficacy. Ann Surg. 2006;244:583-92.

4. Schaefer A, Schofer N, Goßling A, Seiffert M, Schirmer J, Deuschl F, et al. Transcatheter aortic valve implantation versus surgical aortic valve replacement in lowrisk patients: a propensity score-matched analysis. Eur J Cardiothorac Surg. September 30, 2019 [Epub ahead of print].
5. Iturra SA, Suri RM, Greason KL, Stulak JM, Burkhart HM, Dearani JA, et al. Outcomes of surgical aortic valve replacement in moderate risk patients: implications for determination of equipoise in the transcatheter era. J Thorac Cardiovasc Surg. 2014; 147:127-32.

6. Badhwar V, Rankin JS, Ad N, Grau-Sepulveda M, Damiano RJ, Gillinov AM et al. Surgical ablation of atrial fibrillation in the United States: trends and propensity matched outcomes. Ann Thorac Surg. 2017;104:493-500.

7. Quader MA, McCarthy PM, Gillinov AM, Alster JM, Cosgrove DM III, Lytle BW, et al. Does preoperative atrial fibrillation reduce survival after coronary artery bypass grafting? Ann Thorac Surg. 2004;77:1514-22; discussion 1522-1524.

8. Ngaage DL, Schaff HV, Barnes SA, Sundt TM III, Mullany CJ, Dearani JA, et al Prognostic implications of preoperative atrial fibrillation in patients undergoing aortic valve replacement: is there an argument for concomitant arrhythmia surgery? Ann Thorac Surg. 2006;82:1392-9.
See Article page 1816.

\section{Commentary: Concomitant atrial fibrillation ablation: The forgotten procedure}

Vito Domenico Bruno, MD, $\mathrm{PhD},{ }^{\mathrm{a}}$ and Mustafa Zakkar, PhD, FRCS ${ }^{b}$

Should we operate on elderly patients? And, if we operate on them, should we provide them with complete treatment of their disease? The answers to these 2 questions seem obvious, and we are convinced that vast majority of the cardiac surgeons would respond affirmatively to both. In reality, however, the problem of combined surgeries in the elderly is multifaceted; not only must we consider operating on an aging and perhaps fragile population, but we also have to perform complex combined procedures and achieve the same results expected in younger patients. From the perspective of surgical risk evaluation, this seems counterintuitive, and several previous articles have reported the

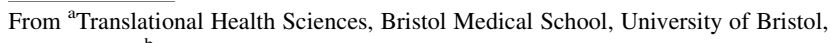
Bristol and ${ }^{\mathrm{b}}$ Department of Cardiovascular Sciences, University of Leicester, Clinical Sciences Wing, Glenfield General Hospital, Leicester, United Kingdom Disclosures: Authors have nothing to disclose with regard to commercial support. Received for publication Oct 28, 2019; revisions received Oct 28, 2019; accepted for publication Oct 28, 2019; available ahead of print Nov 21, 2019.

Address for reprints: Vito Domenico Bruno, MD, PhD, Bristol Medical School Translational Health Sciences, University of Bristol, Research Floor Level 7, Bristol Royal Infirmary, Upper Maudlin St, BS2 8HW, Bristol, United Kingdom (E-mail: Vito.D.Bruno@bristol.ac.uk).

J Thorac Cardiovasc Surg 2021;161:1825-6

$0022-5223 / \$ 36.00$

Copyright (C) 2019 by The American Association for Thoracic Surgery

https://doi.org/10.1016/j.jtcvs.2019.10.178

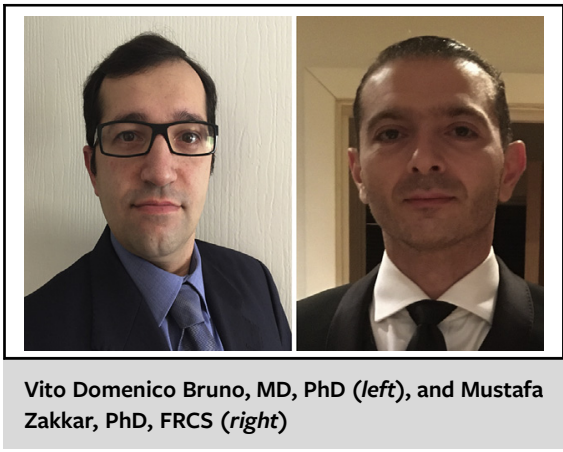

CENTRAL MESSAGE

Is concomitant atrial fibrillation ablation a procedure that should be considered in elderly patients?

negative impact of age on the postoperative outcomes after cardiac surgery. Therefore, we should always carefully estimate the risk-benefit balance in these very delicate patients.

Regarding surgical ablation of atrial fibrillation (AF), prolonging an operation to treat a "minor" problem might be considered inappropriate in these patients. But is AF really a "minor" problem? Previous studies have clearly shown that if left untreated, AF after cardiac surgery has a negative impact on life expectancy and stroke rate. ${ }^{1}$ The study of Petersen and colleagues ${ }^{2}$ can certainly aid the decision of when to pursue treatment of this frequently forgotten disorder. It demonstrates that concomitant $\mathrm{AF}$ 